\title{
Upper incisor to Soft Tissue Plane (UI-STP): A new reference for diagnosis and planning in dentofacial deformities
}

\author{
Federico Hernández-Alfaro ${ }^{1}$ \\ ${ }^{1}$ MD, DDS, PhD, FEBOMS. Clinical Professor Oral and Maxillofacial Surgery, Universitat Internacional de Catalunya. Director \\ Instituto de Cirugía Maxilofacial, Teknon Medical Center, Barcelona,Spain
}

Correspondence:

Instituto de Cirugía Maxilofacial e Implantología

Centro MédicoTeknon

C/Vilana 12

08022 Barcelona, Spain

director@institutomaxilofacial.com

\begin{abstract}
Hernández-Alfaro A. Upper incisor to Soft Tissue Plane (UI-STP): A new reference for diagnosis and planning in dentofacial deformities. Med Oral Patol Oral Cir Bucal. 2010 Sep 1;15 (5):e779-81.

http://www.medicinaoral.com/medoralfree01/v15i5/medoralv15i5p779.pdf
\end{abstract}

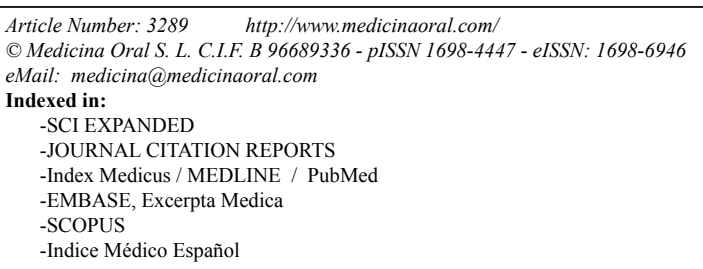

\begin{abstract}
Planning in orthognathic surgery has been and still is an open issue. We have evolved from 2D classical cephalometric hard-tissue planning to 2D soft tissue planning, and finally to 3D and hard and soft tissue evaluation. This, to our knowledge, is the first description of a new Soft Tissue Plane (STP) and its relationship with the anterior position of the upper incisor (UI). Profile photographs of 110 "attractive individuals" with lips at rest or smiling and with upper incisor shown were used. The photographs used were of 65 professional models from two international agencies and 45 individuals considered most attractive in the internet forums, which included catwalk models and actors. In 86 cases (78.18 \%), the incisor was located in front of the STP (A). In 15 cases (13.63\%), it was on the plane $(\mathrm{N})$; and in the remaining 9 cases $(8.18 \%)$, it was behind (P). Despite the limitations of this study and based on our series, we can conclude that the upper incisor is located at or in front of the Soft Tissue Plane (STP) in $91.81 \%$ of the attractive facial profiles studied. On the other hand, the relative position of the upper incisor to the soft tissue plane (UI-STP) could be a useful diagnostic and planning tool in orthodontic and surgical management of dentofacial deformities.
\end{abstract}

Key words: Cephalometry, orthognathic surgery, facial soft tissue, upper incisor, facial analysis.

\section{Introduction}

Planning in orthognathic surgery has been and still is an open issue. We have evolved from $2 \mathrm{D}$ classical cephalometric hard-tissue planning, to 2D soft tissue planning, and finally to 3D and hard and soft tissue evaluation (1). In all cases the goal has been to establish normative data that could be used by clinicians to diagnose and treatment plan for facial deformities.

There are two important limitations. Most of the "classic" cephalometric analyses reflect a norm derived from a limited number of average individuals - not necessarily attractive- with normal occlusions. In the other hand, when different cephalometric analyses are applied to a particular individual, diagnosis and thus treatment plan may vary between them (2). These analyses can at best enhance orthodontic diagnosis and treatment planning. But they are used mainly for descriptive purposes. Individual tracings are compared to an average facial pattern and the difference between them requires considerable interpretation.

The works by Farkas et al. (3) and the posterior developments by authors like Holdaway $(4,5)$, Merrifield (6) and Arnett et al. $(7,8)$ brought the attention to soft tissues (facial mask) in aesthetic diagnosis and planning 
for patients with dentofacial deformities. Sarver et al. (9) introduced the concept of centripetal construction of the face so that the soft tissues should guide skeletal correction.

One of the key points in diagnosis and planning for dentofacial deformities is the $3 \mathrm{D}$ position of the upper incisor (UI). In fact authors like Wolford start their Visual Treatment Objective at this point (10).

There is enough literature and consensus regarding the vertical position of the incisor with relation to the upper lip both at rest and during the smile. Also there are guidelines regarding the sagital position of the UI related to skeletal landmarks (11-14). However, to our knowledge, no previous analysis has established the relationship between the upper incisor and a soft tissue reference like the Soft Tissue Plane.

When planning orthognathic cases in our practice, we subjectively considered that the upper incisor should be in front of a line (plane) passing trough the soft tissue nasion perpendicular to the floor with the head in the natural rest position. Our aim with this study was to establish a rational for this approach by evaluating this Upper Incisor to -what we call- Soft Tissue Plane in a group of uber-atractive individuals.

\section{Material and Method}

Profile photographs of 110 "attractive persons" with lips at rest or smiling and with upper incisor show were used. Photographs belonged to 65 professional models from two international agencies and 45 persons considered as most attractive in the internet forums, and included catwalk models, and actors.

Inclusion criteria were race (caucasian and hispanic) and age (20 to 50).

Exclusion criteria were pictures were poor quality could not clearly yield the soft tissue nasion $\left(\mathrm{N}^{\prime}\right)$ or the anterior limit of the upper incisor.

Maloclussion could not be ruled out from the pictures. All photographs were digitalized and corrected subjectively to natural head position (15) by rotating them. Five independent -non professional- evaluators did the correction on each case. Using the tip of the nose as a center of rotation, evaluators were asked to rotate the picture to a position considered as natural rest position. A vertical line or Soft Tissue Plane (STP) was drawn on each case passing through the soft tissue nasion ( $\left.N^{\prime}\right)$, and descending perpendicular to the base of the photograph. The sagital (Antero-posterior) relation with the anterior limit of the upper incisor was evaluated (Fig. 1). Cases were classified as A (anterior) if the incisor was anterior to the line, $\mathrm{N}$ (neutral) if it was coincident with the line, and $\mathrm{P}$ (posterior) when it was behind the line. No measurements could be taken because of lack of relative size scales in the photographs. Subjects of the study, for obvious reasons were not measured.

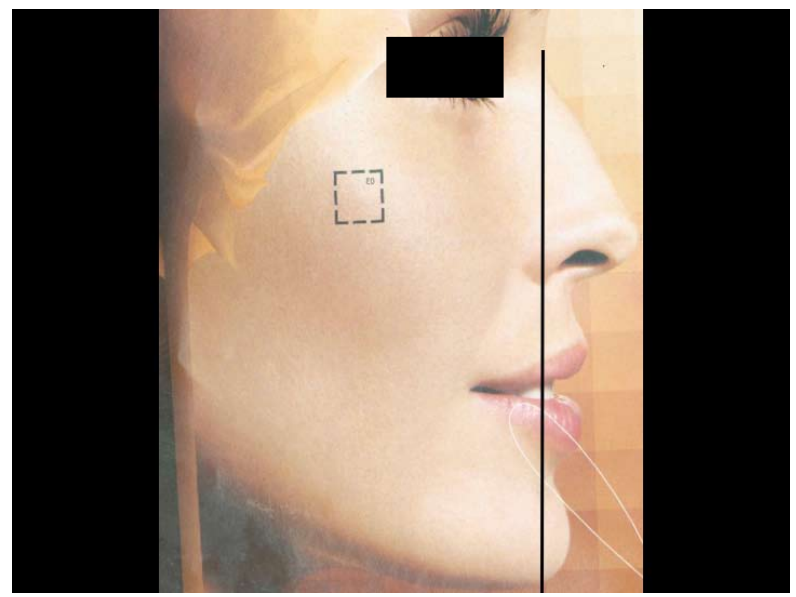

Fig. 1. A vertical line or Soft Tissue Plane (STP) is drawn passing through the soft tissue nasion (N'), and descending perpendicular to the base of the photograph. The sagital (Antero-posterior) relation with the anterior limit of the upper incisor is evaluated.

\section{Results}

67 women, 43 men were included. Mean age ranged between 21 and 50 (mean 28).

Evaluation of the relative sagital position of the most anterior limit of the upper incisor and the Soft Tissue Plane (STP), yielded the following results:

In 86 cases $(78,18 \%)$ the incisor was located in front of the STP (A). In 15 cases $(13,63 \%)$ it was on the plane $(\mathrm{N})$, and in the remaining 9 cases $(8,18 \%)$ it was behind (P). As mentioned earlier, no measurements could be taken from the photographs.

Considering gender, the results were as follows: Males $(\mathrm{n}=43) \mathrm{A}=32, \mathrm{~N}=7, \mathrm{P}=4$. Females $(\mathrm{n}=67) \mathrm{A}=54, \mathrm{~N}=8$, $\mathrm{P}=5$.

\section{Discussion}

Previous descriptions of sagital reference lines and planes, include the so called "true vertical line" (TVL) which is a line perpendicular to the floor which passes through the subnasale (SN) and travels perpendicular to the floor (with the patient in natural rest position. $(7,8)$. Arnett has to be commended for being the first author who truly systematized a comprehensive soft tissue analysis both in the frontal and sagital planes. However, the normative data for Arnett's analysis were drawn from a rather small sample of "attractive" subjects according to the author. In the other hand this line does not constitute an stable reference considering that a great number of disharmonic surgical patients have varying degrees of maxillary hipoplasia (92\% in our 1600 cases experience). These facts prevent the use of this line as an absolute reference.

This is the first description to our knowledge of a new Soft Tissue Plane (STP), and its relation with the ante- 
rior position of the upper incisor (UI). It is unique in that it relates a soft tissue reference, with a hard tissue landmark. Moreover, this correlation, allows for clinical profile evaluation without the need of a radiograph.

Numerous attempts at measuring beauty have failed. Human faces have one thing in common: They're all different. Variation is the norm and should be embraced. However we can set some 3D references obtained from attractive individuals that help to reduce subjectivity. Our upper incisor to Soft Tissue Plane relation could be one of them.

We strongly believe that -when diagnosing and planning for dentofacial deformities- one should bear in mind that occlusal and frontal parameters are objective. In other words malocclusions and asymmetries can be precisely quantified with numbers. In the other hand vertical and anteroposterior parameters are subjective and it has no sense trying to quantify them to the millimeter. These parameters are responsible for the "artistic" and individualized treatment plan that each patient deserves.

Treatment planning should be based on achieving optimal aesthetics and function for each patient rather than following anatomical norms of occlusion and facial balance. In order to have a real set of norms that could be really helpful we should implement a gigantic database with thousands of individuals classified by age, sex, and race. Only in this scenario normative data could be trusted. But even in this case final tuning of the treatment plan in the vertical and anteroposterior dimensions should rely on a subjective approach. Each patient deserves a tailored solution. Our UI-STP relationship does not establish a precise to-the-milimeter rule to plan for ortho-surgical cases. Instead it sets a tendency that should be incorporated to the subjective treatment plan.

Limitations of our study include the following: we only had profile non-calibrated photographs of the subjects of study, thus only absolute non-numeric evaluations could be done. Also there is some subjectivity in positioning the pictures with the adequate rotation. Using independent professional observators probably helped to neutralize the bias. Other limitation is the sample of subjects. However it is still bigger than most of the previous studies on facial diagnosis $(7,8)$. A last limitation is that maloclussions were not specifically excluded. However one could assume that most of the selected -uber-atractive-subjects have rather normal (treated or not) occlusions.

With the limitations of this study, we can conclude that, in our series 91,81 of the attractive facial profiles have their upper incisor at or in front of the Soft Tissue Plane (STP). In the other hand, the relative position of the upper incisor to the soft tissue plane (UI-STP) could be a useful diagnostic and planning tool in orthodontic and surgical management of dentofacial deformities.

\section{References}

1. Incrapera AK, Kau CH, English JD, McGrory K, Sarver DM. Soft tissue images from cephalograms compared with those from a 3D surface acquisition system. Angle Orthod. 2010;80:58-64.

2. Wylie GA, Fish LC, Epker BN. Cephalometrics: a comparison of five analyses currently used in the diagnosis of dentofacial deformities. Int J Adult Orthodon Orthognath Surg. 1987;2:15-36.

3. Farkas LG, Eiben OG, Sivkov S, Tompson B, Katic MJ, Forrest CR. Anthropometric measurements of the facial framework in adulthood: age-related changes in eight age categories in 600 healthy white North Americans of European ancestry from 16 to 90 years of age. J Craniofac Surg. 2004;15:288-98.

4. Holdaway RA. A soft-tissue cephalometric analysis and its use in orthodontic treatment planning. Part I. Am J Orthod. 1983;84:1-28.

5. Holdaway RA. A soft-tissue cephalometric analysis and its use in orthodontic treatment planning. Part II. Am J Orthod. 1984;85:27993.

6. Merrifield LL. The profile line as an aid in critically evaluating facial esthetics. Am J Orthod. 1966;52:804-22.

7. Arnett GW, Bergman RT. Facial keys to orthodontic diagnosis and treatment planning. Part I. Am J Orthod Dentofacial Orthop. 1993;103:299-312.

8. Arnett GW, Bergman RT. Facial keys to orthodontic diagnosis and treatment planning--Part II. Am J Orthod Dentofacial Orthop. 1993;103:395-411.

9. Sarver DM, Rousso DR. Plastic surgery combined with orthodontic and orthognathic procedures. Am J Orthod Dentofacial Orthop. 2004;126:305-7.

10. Wolford LM, Chemello PD, Hilliard FW. Occlusal plane alteration in orthognathic surgery. J Oral Maxillofac Surg. 1993;51:73040.

11. Steiner CC. [Importance of cephalometry in orthodontic treatment]. Inf Orthod Kieferorthop. 1969;1:3-12.

12. Ricketts RM. Perspectives in the clinical application of cephalometrics. The first fifty years. Angle Orthod. 1981;51:115-50.

13. McNamara JA Jr. A method of cephalometric evaluation. Am J Orthod. 1984;86:449-69.

14. Downs WB. Variations in facial relationships; their significance in treatment and prognosis. Am J Orthod. 1948;34:812-40.

15. Moorrees CF. Natural head position--a revival. Am J Orthod Dentofacial Orthop. 1994;105:512-3. 